\title{
Hyperlipidemic Pancreatitis: Prevalence, Presentation and Outcome
}

\author{
Munaser S. Alamoodi \\ Faculty of Medicine, Department of Surgery, King Abdulaziz University, Jeddah, Saudi Arabia \\ Email: munas88@yahoo.com
}

Received 11 December 2015; accepted 22 January 2016; published 25 January 2016

Copyright (C) 2016 by author and Scientific Research Publishing Inc.

This work is licensed under the Creative Commons Attribution International License (CC BY).

http://creativecommons.org/licenses/by/4.0/

c) (i) Open Access

\section{Abstract}

Background: This study was done to determine uncommon causes of acute pancreatitis to improve outcome of management. Aim: The aim is to determine the prevalence, clinical presentation, and outcome of hyperlipidemic pancreatitis in a single academic institute. Patients and methods: Records of 81 patients admitted with acute pancreatitis to King Abdulaziz University hospital were looked at retrospectively between June 2010 and Sept 2012. Data were collected which included the demographics, clinical presentation, amylase level on admission, findings of the computed tomography (CT) scan, intensive care (ICU) admission and length of hospital stay. Patients were then categorized into three categories: patients with first attack (group A), those with recurrent attacks (group B) and those with readmission with a second attack from group A (group C). Results: Out of 81 patients, $7(10 \%)$ patients were found to have hyperlipidemic pancreatitis. Age range was 21 68 years (mean $=44.5$ ). The male patients were 4 and the females were 3 . All patients presented with epigastric pain. Four patients were in group $A$ while 3 patients were in group $B$ and, 3 patients in group $C$. Group $C$ is the recurrence from group $A 3$ out of 4 patients. The amylase ranged $170-220 \mathrm{IU} / \mathrm{L}$ in group $\mathrm{A}$, compared to group B which was $1200-2500 \mathrm{IU} / \mathrm{L}$ and, group $\mathrm{C}$ amylase levels were $1100-2000 \mathrm{IU} / \mathrm{L}$. None of the patients in group A were known to have hypertriglyceridemia (HTG), while all in group B and C were known to have HTG. The level of triglyceride (TG) in all the groups was raised ranging from 12.5 - $20.2 \mathrm{mmol} / \mathrm{l}$. Diabetes was present in 3 of group $A$ patients, non in group $B$ and, all of group $C$ in which was not controlled by medications. CT grading (Balthazar Index) was B for groups A and B, while for patients in group $C$ it was $C$ with $30 \%$ necrosis. No ICU admission was required for patients in group $A$ and $B$, while all the patients in $C$ needed ICU admission. Hospital stay was 3 - 5 days for group A, 7 - 10 days for group B and 7 - 12 days for group C. Conclusion: Prevalence of hyperlipidemic pancreatitis was found to be $10 \%$. Patients with first attack presented with mild to moderate attack and a favorable outcome. A second attack was often severe and was associated with necrosis. Patients with a second attack should be closely monitored as they might need an ICU setting. 


\section{Keywords}

\section{Acute Pancreatitis, Hypertriglyceridemia, Amylase, Necrosis}

\section{Introduction}

Acute pancreatitis (AP) is a common surgical condition necessitating admission. Non biliary causes are generally overlooked and patients experience recurrent episodes and multiple admissions. Readmission with second attack can carry high morbidity and mortality. The cases of hyperlipidemic pancreatitis if not properly investigated are liable for recurrent attacks. The causes of acute pancreatitis (AP) range from surgical causes to medi$\mathrm{cal}$. The commonest cause is gallstones while the third commonest is said to be hyperlipidemia [1] [2]. Most of AP cases fall into the mild to moderate severity class, $20 \%$ fall into the severe category with mortality of $5 \%$. AP is mainly seen in hypertriglyceridemia (HTG) and not hypercholesterolemia [2]. The AP course is usually mild to moderate when caused by HTG. The typical patients are usually known to have HTG with an identifiable secondary factor (e.g. poorly controlled diabetes, alcohol use, or medication) that can induce HTG. Triglyceride level of more than $11.3 \mathrm{mmols} / \mathrm{l}$ in patients with type I, IV or hyperlipidemia (Fredrickson's classification) is an identifiable risk factor [3]. An increase in the volume of intra-pancreatic adipocytes is associated with more extensive pancreatic necrosis during AP [4]. The employment of lipid lowering agents and dietary control constitutes the mainstay of treatment [5]. The patients who do not respond to these medications are acutely ill, more measures are required in the form of plasmapharesis (PP). PP is an effective and safe method in reducing triglycerides leading to early recovery in otherwise very sick patients [6]-[9]. Insulin and heparin infusion is also an effective way in reducing triglycerides as it enhances the function of lipoprotein lipase [10]. The objective to write this paper is to detect pancreatitis that is caused by hyperlipidemia. Hyperlipidemic pancreatitis can cause considerable recurrence and recurrence can lead to considerable morbidity and mortality.

\section{Patients and Methods}

Records of 81 patients admitted with acute pancreatitis to King Abdulaziz University hospital were looked at retrospectively between June 2010 and Sept. 2012. Those with the cause due to hyperlipidemia were included in this study. Diagnostic criteria were to find two of the following three-1) Typical abdominal pain; 2) Elevation of amylase or lipase more than three times of its normal value; 3) Characteristic CT Grading. Serum samples for triglycerides were taken on admission. Serum triglycerides were found to be raised from 12.5 to $20.2 \mathrm{mmol} / \mathrm{l}$. Data collected included the demographics, clinical presentation, amylase level on admission, findings of the CT scan, ICU admission and length of hospital stay. Any secondary factors known to cause hyperlipidemia were looked at, as well as relevant drug history. Detailed medical history regarding hyperlipidemia, hypertension and ischemic heart diseases was taken. The patients were then categorized into three groups: patients with a first attack (group A), those with recurrent attacks (group B) and those with readmission with a second attack from group a (group C). Patients with second attack from group A were closely followed as they had increased morbidity and required ICU admission. Ethical clearance was obtained by ethical committee prior to starting research work.

\section{Results}

Out of 81 patients, 7 (10\%) were found to have hyperlipidemic pancreatitis. Age range was 21 - 68 years (mean $=44.5$ ). The male patients were 4 and the females were 3 . All presented with epigastric pain (Table 1 ). Four

Table 1. Summary of the data collection (7/81 patients).

\begin{tabular}{cccccc}
\hline Age & Sex & $\begin{array}{c}\text { Epigastric } \\
\text { pain }\end{array}$ & $\begin{array}{c}\text { First attack (n), as } \\
\text { the first admission } \\
\text { (group A) }\end{array}$ & $\begin{array}{c}\text { Recurrent attack (n), as } \\
\text { the first dmission } \\
\text { (group B) }\end{array}$ & $\begin{array}{c}\text { Recurrent attack (n), as the second admission. } \\
\text { Patients from group A forming (C) }\end{array}$ \\
\hline $21-68$ & $\begin{array}{l}\mathrm{M}=4 \\
\mathrm{~F}=3\end{array}$ & All & 4 & 3 \\
\hline
\end{tabular}


were in group A while 3 were in group B and, 3 in group C. Group C had 3 patients from group A. so total number of patients who had hyperlipedemic pancreatitis was 7 . The amylase ranged $170-220 \mathrm{IU} / \mathrm{l}$ in group A, compared to group B which was 1200 - 2500 and, group C amylase levels were 1100 - 2000. None of the patients in group A were known to have hypertriglyceraldemia (HTG), while all in group B and C were known to have HTG. The levels of TG in all the groups was raised ranging from $12.5-20.2 \mathrm{mmol} / \mathrm{l}$. Diabetes was present in 3 of group A patients, non in group B and, all of group C in which was not controlled by medications. CT grading (Balthazar Index) was applied for all patients as it is sensitive in predicting the course of pancreatitis and to monitor closely those patients with high Balthazar score. It was B for groups A and B, while for patients in group C it was C with 30\% necrosis. No ICU admission was needed for patients in group A, 1 (14\%) of B, and the 3 (43\%) patients in C needed ICU admission. The length of hospital stay was shortest for group A and similar for the remaining groups (Table 2). Recurrence of pancreatitis was severe, which required ICU admission and plasmapheresis with improved results.

\section{Discussion}

Hypertriglyceraldemia (HTG) is the cause of AP in 4\% - 5\% [11]. In another study it was found to cause $12 \%$ $38 \%$ [2]. In our study, HTG is the cause of acute pancreatitis in $10 \%$ of cases. In most cases the patients fall into the category of known hyperlipidemia on presentation. The majority of patients in this study were discovered for hyperlipidemia the first time in their presentation. They were also found to be young. This cause can be easily over looked and labeled as idiopathic unless otherwise thoroughly investigated. High level of clinical suspicion is required to reach a diagnosis in such patients presenting with typical clinical settings. The diagnosis is challenging due to the normal or mildly raised amylase [12]. The amylase was found to be within normal levels in the patients who presented for the first time. Subsequent admissions showed raised diagnostic levels of amylase. Although the clinical course was suggested to be mild to moderate in most cases due to HTG this study found that with a second recurrence the attack is often severe. This was reflected by the CT findings which showed the presence of necrosis and the need for ICU admission. Forston et al. suggested that there is no clear evidence that hyperlipidemia induced pancreatitis differs from other types of pancreatitis in terms of frequency of necrosis, complications or outcome. Our study found the contrary. The CT evidence and ICU admissions mentioned before suggest that patients are prone to a more severe presentation in a second attack. Nearly all the patients with a second admission had uncontrolled diabetes which could be the triggering factor for the HTG leading to AP [13]. The attacks took place despite the fact that these patients were on lipid lowering medication. The triggering factors were commonly found to be dietary and obesity [14]. For triglycerides levels to exceed $20 \mathrm{mmols} / \mathrm{l}$, most patients will have some form of primary or genetic defect in lipid metabolism. Genetic factors determine over 60\% of the variability in serum lipids. Mutations in lipoprotein lipase gene have been identified in patients with HTG-induced pancreatitis [15]. O’Brien et al. found hypothyroidism to have a well established association with hyperlipidemia. Elevations of triglyceride levels are observed in up to $35 \%$ of hypothyroid patients [16]. It is imperative hence that members of a family are screened. The fibric acid derivatives (fibrates), such as Gemfibrozil are the drugs of first choice. Lipid lowering toward normal was achieved in all patients with a program of combined dietary and drug therapy [17]. Heaney et al. found that in familial lipoprotein lipase deficiency who remained markedly hypertriglyceridemic after medical therapy, anti-oxidant therapy (selenium, vitamin c, and beta-carotene) has been used with success [18]. Limitation of study was the small number of patients in the study which is due to uncommon cause of acute pancreatitis.

\begin{tabular}{|c|c|c|c|c|c|c|c|c|}
\hline Patient groups & $\begin{array}{c}\text { Amylase } \\
\text { level (IU/L) }\end{array}$ & $\begin{array}{l}\text { Known } \\
\text { HTG }\end{array}$ & $\begin{array}{l}\text { Unknown } \\
\text { HTG }\end{array}$ & $\begin{array}{c}\text { Level of } \\
\text { TG }(\mathrm{mmol} / \mathrm{l})\end{array}$ & $\begin{array}{l}\text { Secondary } \\
\text { factors }\end{array}$ & $\begin{array}{c}\mathrm{CT} \\
\text { grading }\end{array}$ & $\begin{array}{c}\text { ICU } \\
\text { admission }\end{array}$ & $\begin{array}{c}\text { Hospital } \\
\text { stay (days) }\end{array}$ \\
\hline $\begin{array}{l}\text { First attack }(\mathrm{n}=4) \\
\quad(\text { group } \mathrm{A})\end{array}$ & $170-220$ & No & Yes & $15.2-20.1$ & $\begin{array}{c}3 \text { had } \\
\text { diabetes }\end{array}$ & All B & Non & $3-5$ \\
\hline $\begin{array}{l}\text { Recurrent attacks } \\
(\mathrm{n}=3) \text { (group B) }\end{array}$ & $1200-2500$ & Yes & No & $12.5-18.5$ & Non & All B & 1 & $7-10$ \\
\hline $\begin{array}{c}\text { Second attack } \\
(\mathrm{n}=3)^{*} \text { (patients } \\
\text { from group A } \\
\text { forming C) }\end{array}$ & $1100-2000$ & Yes & No & $12.5-20.2$ & $\begin{array}{c}\text { All diabetic } \\
\text { (uncontrolled) }\end{array}$ & $\begin{array}{l}\text { C, } 30 \% \\
\text { necrosis }\end{array}$ & 3 & $7-12$ \\
\hline
\end{tabular}

*The patients are those who initially had the first attack. 


\section{Conclusion}

Prevalence of hyperlipidemic pancreatitis was found to be $10 \%$. Patients with first attack presented with mild to moderate attack and a favorable outcome. A second attack was often severe and might be associated with necrosis. Patients with a second attack should be closely monitored and might need an ICU setting. A larger study is needed to confirm this phenomenon.

\section{Conflict of Interest Statement}

The author (Munaser Alamoodi) has no conflict of interest and no source of support.

\section{References}

[1] Fortson, M.R., Freedman, S.N. and Webster, P.D. (1995) Clinical assessment of Hyperlipidemic Pancreatitis. The American Journal of Gastroenterology, 90, 2134-2139.

[2] Toskes, P.P. (1990) Hyperlipidemic Pancreatitis. Gastroenterology Clinics of North America, 19, $783-791$.

[3] Berglund, L., Brunzell, J.D., Goldberg, A.C., Goldberg, I.G., Sacks, F., Murad, M.H., et al. (2012) Evaluation and Treatment of Hypertriglyceridemia: An Endocrine Society Clinical Practice Guideline. The Journal of Clinical Endocrinology \& Metabolism, 97, 2969-2989. http://dx.doi.org/10.1210/jc.2011-3213

[4] Navina, S., Acharya, C., DeLany, J.P., Orlichenko, L.S., Baty, C.J., Shiva, S.S., et al. (2011) Lipotoxicity Causes Multisystem Organ Failure and Exacerbates Acute Pancreatitis in Obesity. Science Translational Medicine, 3, 107-110. http://dx.doi.org/10.1126/scitranslmed.3002573

[5] Preiss, D., Tikkanen, M.J., Welsh, P., Ford, I., Levato, L.C., Elam, M.B., et al. (2012) Lipid-Modifying Therapies and Risk of Pancreatitis: A Meta-Analysis. JAMA, 308, 804-811. http://dx.doi.org/10.1001/jama.2012.8439

[6] Yeh, J.H., Lee, M.F. and Chiu, H.C. (2003) Plasmapheresis for Severe Lipemia: Comparison of Serum-Lipid Clearance Rates for the Plasma-Exchange and Double-Filtration Variants. Journal of Clinical Apheresis, 18, 32-36. http://dx.doi.org/10.1002/jca.10047

[7] Furuya, T., Komatsu, M., Takahashi, K., Hashimoto, N., Hashizume, T., Wajima, N., et al. (2002) Plasma Exchange for Hypertriglyceridemic Acute Necrotizing Pancreatitis: Report of Two Cases. Therapeutic Apheresis, 6, 454-458. http://dx.doi.org/10.1046/j.1526-0968.2002.00461.x

[8] Stefanutti, C., Di Giacomo, S. and Labbadia, G. (2011) Timing Clinical Events in the Treatment of Pancreatitis and Hypertriglyceridemia with Therapeutic Plasmapheresis. Transfusion and Apheresis Science, 45, 3-7. http://dx.doi.org/10.1016/j.transci.2011.06.013

[9] Kyriakidis, A.V., Raitsiou, B., Sakagianni, A., Harisopoulou, V., Pyrgioti, M., Panagopoulou, A., et al. (2006) Management of Acute Severe Hyperlipidemic Pancreatitis. Digestion, 73, 259-264. http://dx.doi.org/10.1159/000095425

[10] Alagözlü, H., Cindoruk, M., Karakan, T. and Unal, S. (2006) Heparin and Insulin in the Treatment of Hypertriglyceridemia-Induced Severe Acute Pancreatitis. Digestive Diseases and Sciences, 51, 931-933. http://dx.doi.org/10.1007/s10620-005-9006-z

[11] Tsuang, W., Navaneethan, U., Ruiz, L., Palascak, J.B. and Gelrud, A. (2009) Hypertriglyceridemic Pancreatitis: Presentation and Management. The American Journal of Gastroenterology, 104, 984-991. http://dx.doi.org/10.1038/ajg.2009.27

[12] Fallat, R.W., Vester, J.W. and Glueck, C.J. (1973) Suppression of Amylase Activity by Hypertriglyceridemia. JAMA, 225, 1331-1334. http://dx.doi.org/10.1001/jama.1973.03220390031007

[13] Lloret Linares, C., Pelletier, A.L., Czernichow, S., Vergnaud, A.C., Bonnefont-Rousselot, D., Levy, P., et al. (2008) Acute Pancreatitis in a Cohort of 129 Patients Referred for Severe Hypertriglyceridemia. Pancreas, 37, $13-2$. http://dx.doi.org/10.1097/MPA.0b013e31816074a1

[14] Sandhu, S., Al-Sarraf, A., Taraboanta, C., Frohlich, J. and Francis, G.A. (2011) Incidence of Pancreatitis, Secondary Causes, and Treatment of Patients Referred to a Specialty Lipid Clinic with Severe Hypertriglyceridemia: A Retrospective Cohort Study. Lipids in Health and Disease, 10, 157. http://dx.doi.org/10.1186/1476-511X-10-157

[15] Jap, T.S., Jenq, S.F., Wu, Y.C., Chiu, C.Y. and Cheng, H.M. (2003) Mutations in the Lipoprotein Lipase Gene as a Cause of Hypertriglyceridemia and Pancreatitis in Taiwan. Pancreas, 27, 122-126.

[16] O’Brien, T., Dinneen, S.F., O’Brien, P.C. and Palumbo, P.J. (1993) Hyperlipidemia in Patients with Primary and Secondary Hypothyroidism. Mayo Clinic Proceedings, 68, 860-866. http://dx.doi.org/10.1016/S0025-6196(12)60694-6

[17] Gavish, D., Eisenberg, S., Berry, E.M., Kleinman, Y., Witztum, E., Norman, J., et al. (1987) Bulimia. An Underlying Behavioral Disorder in Hyperlipidemic Pancreatitis: A Prospective Multidisciplinary Approach. Archives of Internal 
Medicine, 147, 705-708. http://dx.doi.org/10.1001/archinte.1987.00370040087015

[18] Heany, A.P., Sharer, N., Rameh, B., Braganza, J.M. and Durrington, P.N. (1999) Prevention of Recurrent Pancreatitis in Familial Lipoprotein Lipase Deficiency with High-Dose Antioxidant Therapy. Journal of Clinical Endocrinology \& Metabolism, 84, 1203-1205. http://dx.doi.org/10.1210/jcem.84.4.5617 